\title{
Mycotoxins effect on male fertility Hormones
}

\author{
Abdel-Razik, M. , *Ayesh, A. and **El-Naggar, M. \\ Medical Microbiology unit, Faculty of Science, Suez Canal University. \\ *Mycotoxin unit, The National Research Center, Dokki, Giza. **Clinical \\ Chemistry Lab, El-Amery public hospital, Port-Said.
}

\begin{abstract}
A total of 12 fungal species belonging to 8 genera were isolated from various collected and examined samples. Fusarium graminearum was grown on suitable medium for crude toxin production, 2ry metabolites were used for treating experimental animal models (not for control). After treatment period blood samples were collected for hormonal assays, Serum testosterone concentration was greatly reduced but follicle stimulating hormone values showed significant increase in treated samples. Testosterone and follicle-stimulating hormone are potential factors required to obtain male fertility and the process of spermatogenesis in the testis
\end{abstract}

\section{Introduction}

Mycotoxins are toxic secondary metabolites produced by fungi (molds) that cause an undesirable effect (mycotoxicosis) when human are exposed. Exposure is usually by consumption of contaminated foods, but may also by contact or inhalation. Biological effects include liver and kidney toxicity, central nervous system effects and estrogenic effects, to name a few. Only some molds produce mycotoxins and they are referred to as toxigenic. The fungal toxins are chemically diverse representing a variety of chemical families and range in molecular weight from about 200 to $500 \mathrm{kD}$. There are hundreds of known mycotoxins, but few have been extensively researched and even fewer have good methods of analysis available. The primary classes of mycotoxins are aflatoxins, zearalenone, trichothecenes, fumonisins, ochratoxin A and the ergot alkaloids. (CAST, 2003).

Testosterone and folliclestimulating hormone (FSH) are required to obtain full reproductive potential. In the tests, somatic Sertoli cells transduce signals of testosterone and FSH resulting the production of factors that are required by germ cells as they mature into spermatozoa (Walker, and Cheng, 2005 )

The present study aimed to clarify the effect of crud toxins on male fertility using experimental model animals

\section{Materials and Methods}




\section{Isolation of fungi}

Three different culture media were used to isolate the fungi: CzapekDox agar, Malt extract-glucose agar and Potato-dextrose agar (PDA). The antibiotic, chloramphenicol, was added at a concentration of 0.5 $\mathrm{mg} / \mathrm{ml}$ medium before autoclaving to suppress bacterial growth. Fungi in the samples were detected and examined using the direct plating method (Flannigan, 1977). Samples of $10 \mathrm{~g}$ of each grains (wheat, barley, rice, maize and sorghum) were surface-sterilized in $1 \% \mathrm{NaOCl}$ for 1 minute and rinsed twice in sterile distilled water. The surface sterilized grains were aseptically transferred onto the solidified agar. A total of 9 plates were plated per sample. Ten grains were plated on each agar plate. Inoculated plates were incubated for seven days at $27^{\circ} \mathrm{C}$ prior to visual differentiation and counting of colonies (Czerwiecki et al, 2002). The different fungal colonies on the plates were subcultured on PDA media for identification of species (Raper and Fennell, 1977; Domsch et al, 1981; Nelson et al, 1983 ; Pitt, 1985, 2000).

Production of 2ry metabolites (crude toxins)

The selected fungus (Fusarium graminearum) was grown on plates of potato dextrose agar for one week, inoculum of the tested fungus was transferred to test tubes containing $10 \mathrm{ml}$ of sterilized phosphate buffered saline mixed thoroughly, then adjusted to approximately $10^{5}$ C.F.U/ml. One $\mathrm{ml}$ of fungul spore suspension was inoculated into autoclaved conical flask containing $100 \mathrm{ml}$ of Sabouraud's dextrose broth liquid media, incubated for 10 days at 28 ${ }^{\circ} \mathrm{C}$, filtered under aseptic conditions using bacterial filter $(0.2$ $\mu 1$ pore size Millipore - USA )

The supernatant was processed for crude toxin determination according to the method of Biuret method (Henry, 1964) using ready made kit (Biocon-Germany).

Protein concentrations was expressed as $\mu \mathrm{g} / \mathrm{dl}$. Then the secondary metabolites were kept in clean sterilized vials in the fridge for experimental procedures.

\section{Treatment of experimental animal :}

Eighteen wister male albino rats (10-12 weeks of age) weighing 120- $150 \mathrm{~g}$ were obtained from animal house research unit at the Egypt National Research Center, Dokki, Giza. The animals were housed in plastic cages with corn cob bedding which was changed weekly. Food and water were provided. Animals were divided into two groups, (9 rats in each group), control and treated. The control animals received normal food and water for 8 weeks. Treated animals received normal Food and water plus oral doses of $1.5 \mathrm{ml}$ fungal secondary metabolites / 100 g body weight/day for 8 weeks. 


\section{Hormonal determination Serum sample}

At the end of the experiment, blood samples from 9 control animals and 9 treated animals were allowed to clot for 30 minutes at $37^{\circ} \mathrm{C}$ before centrifugation for 15 minutes at $1000 \mathrm{x}$ g. to obtain serum then stored at $-20^{\circ} \mathrm{C}$.

Quantitative measurement of rat follicle stimulating hormone by ELISA system (Closset, and Hennen 1988 and Teerds, et al, 1989).

Quantitative determination of testosterone in serum by enzyme immunoassay system (Zirkin, and Chen, 2000 and Sakuma, 2009).

\section{Results}

\section{Fungi isolated from various} samples:

As shown in Table 1, a total of 12 species of fungi belonging to 8 genera were isolated and identified from wheat, barley, rice, sorghum and maize. two species of Aspergillus (A.flavus and A.niger); Two species of Penicillium ( $P$. digitatum and $P$. notatum); Three Fusarium species ( $F$. graminearum, $F$. moniliforme and $F$. solani); one Cladosporium species ( $C$. herbarum).; one species of Alternaria (A. altrnata); one species of Rhizopus (R. stolonifer); one species of Tricoderma ( $T$. viridi); and one species of Cunninghamella ( $C$. elegans).

Aspergillus (A.flavus and A.niger) and Fusarium moniliforme were the most commonly isolated fungi from all the tested samples followed by Penicillium notatum which was isolated from 4 samples (wheat, barley, sorghum and maize); Tricoderma viridi was isolated from 4 samples (wheat, barley, rice and sorghum); Penicillium digitatum was commonly isolated from 3 samples (wheat, sorghum and maize); Alternaria altrnata was isolated from 3 samples (wheat, barley and sorghum); Fusarium graminearum was isolated from 2 samples (barley and rice); Cladosporium herbarum commonly isolated from 2 samples (wheat and rice); Rhizopus stolonifer was isolated from 2 samples (wheat and barley); Fusarium solani was commonly isolated from only 1 sample (barley); Cunninghamella elegans was isolated from only 1 sample (sorghum) .

Production of 2ry metabolites (crude toxins)

The concentration of fungal ( crud toxin ) in terms of protein content in the fungal 2ry metabolites determined by spectrrophotometric method megarments was equal to $637 \mu \mathrm{g} / \mathrm{dl}$

\section{Testosterone measurements}

Table 2 and Figure 1 showed that the mean concentration of serum testosterone in treated experimental animal model was greatly reduced $(\mathrm{P}<0.01) \quad$ compared to the control group $(0.57,4.46 \mathrm{ng} / \mathrm{ml}$, respectively). 
Follicle stimulating hormone showed increased value $(\mathrm{P}<0.01)$ in measurements

treated experimental animal model

Mean value of follicle stimulating than in case of control

(9.143, hormone (Tables 2 and Figure 1 ) $4.020 \mathrm{ng} / \mathrm{ml}$, respectively)

Table 1. Frequency distribution of fungi isolated from samples

\begin{tabular}{|l|l|l|l|l|l|l|}
\hline Fungi Samples & wheat & barley & rice & sorghum & maize & $\begin{array}{l}\text { Total } \\
\text { No. }\end{array}$ \\
\hline Aspergillus flavus & + & + & + & + & + & $\mathbf{5}$ \\
\hline Aspergillus niger & + & + & + & + & + & $\mathbf{5}$ \\
\hline Penicillium digitatum & + & - & - & + & + & $\mathbf{3}$ \\
\hline Penicillium notatum & + & + & - & + & + & $\mathbf{4}$ \\
\hline $\begin{array}{l}\text { Fusarium } \\
\text { graminearum }\end{array}$ & - & + & + & - & - & $\mathbf{2}$ \\
\hline Fusarium moniliforme & + & + & + & + & + & $\mathbf{5}$ \\
\hline Fusarium solani & - & + & - & - & - & $\mathbf{1}$ \\
\hline $\begin{array}{l}\text { Cladosporium } \\
\text { herbarum. }\end{array}$ & + & - & + & - & - & $\mathbf{2}$ \\
\hline Alternaria altrnata & + & + & - & + & - & $\mathbf{3}$ \\
\hline Rhizopus stolonifer & + & + & - & - & - & $\mathbf{2}$ \\
\hline Tricoderma viridi & + & + & + & + & - & $\mathbf{4}$ \\
\hline $\begin{array}{l}\text { Cunninghamella } \\
\text { elegans }\end{array}$ & - & - & - & + & - & $\mathbf{1}$ \\
\hline
\end{tabular}

Table (2) Statistical analysis for the effect of crude toxin on hormonal level in control and treated samples

\begin{tabular}{|l|l|l|}
\hline & $\begin{array}{l}\text { Mean testosterone } \\
\text { level } \\
(\mathbf{n g} / \mathbf{m l})\end{array}$ & $\begin{array}{l}\text { Mean follicle stimulating } \\
\text { hormone level }(\mathbf{n g} / \mathbf{m l})\end{array}$ \\
\hline Control & $\mathbf{4 . 4 6 7}$ & $\mathbf{4 . 0 2 0}$ \\
\hline Treated & $\mathbf{0 . 5 7 7} * *$ & $\mathbf{9 . 1 4 3} * *$ \\
\hline
\end{tabular}

** Significant at $1 \%$ level $(\mathrm{P}<0.01)$ 


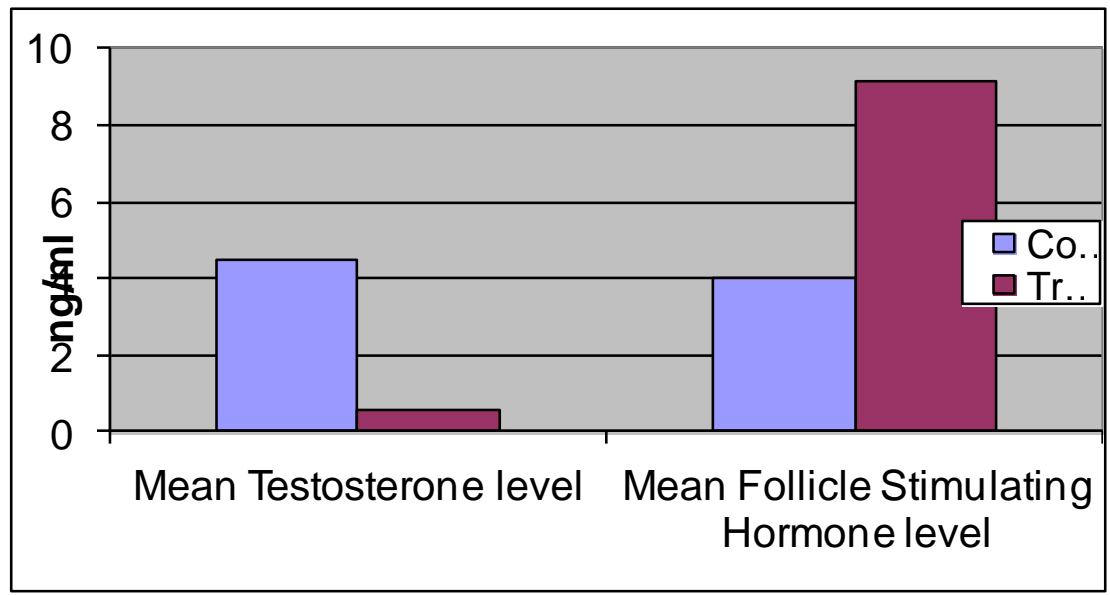

Figure (1) The effect of crude toxin on hormonal level in control and treated samples .

\section{Discussion}

Many species of fungi produce mycotoxins in food. Molds can grow and mycotoxins can be produced during storage and transport. Mold growth and mycotoxin production are related. To inadequate storage conditions . environmental conditions, e.g. heat, water and insect damage consider a predisposeing factor in mycotoxin production and concentrations (Dowd, 2004).

Molds can grow over a temperature range of $10-40^{\circ} \mathrm{C}$, a $\mathrm{pH}$ range of $4-8$ and $12-15 \%$ moisture. The conditions most suitable for mold growth and for mycotoxin formation are not necessarily the same. The Fusarium molds associated with Alimentary Toxic Aleukia have been reported to grow prolifically at $25-30^{\circ} \mathrm{C}$ without producing much mycotoxin, but at near freezing temperatures, they produce large quantities of mycotoxins with minimal mold growth (Joffe, 1986). In the present study a total of 12 fungal species belonging to 8 genera were isolated and identified from the examined samples; wheat, barley, rice, sorghum and maize. The isolated fungi included two species of Aspergillus (A.flavus and A.niger); two species of Penicillium ( $P$. digitatum and $P$. notatum); three Fusarium species $(F$. graminearum, $F$. moniliforme and $F$. solani); one Cladosporium species ( $C$. herbarum).; one species of Alternaria (A. altrnata); one species of Rhizopus (R. stolonifer); one species of Tricoderma (T. viridi); one species of Cunninghamella (C. elegans). Aspergillus and Fusarium were the most commonly isolated fungi from the collected and examined grains followed by Penicillium notatum . 
Fusarium species are ubiquitous in soils. They are commonly considered as field fungi invading more than $50 \%$ of the crop grains before harvest (RobledoRobledo,1991) and a main cause of diseased maize and wheat (Doko et al, 1996, Munkvold and Desjardins, 1997, and Orsi et al, 2000). Grains contamination by fungi not only renders grains unfit for human consumption by discoloration and reduction of nutritional value, but can also lead to mycotoxin production. Mycotoxins are poisonous secondary metabolites produced by some fungi in staple foods and foodstuffs. (Pitt, 2000).

Testosterone and folliclestimulating hormone (FSH) are required to obtain full reproductive potential. In the tests, hormonal harmony are required by germ cells as they mature into spermatozoa (Walker, and Cheng, 2005).

On average, in adult males, levels of testosterone are about 7-8 times as great as in adult females, but, as the metabolic consumption of testosterone in males is greater, the daily production is about 20 times greater in men. Females are also more sensitive to the hormone. Testosterone is observed in most vertebrates. (Mechoulam et al, 1984).

The in vivo experiment in this study showes obvious and significant reduction in mean concentration of serum testosterone level in treated experimental animal model in case of control than treated $(0.57,4.46$ $\mathrm{ng} / \mathrm{ml}$ ) respectively . Also the obtained results indicate that the mean value of follicle stimulating hormone was significantly increased in treated experimental animal model than in case of control $\quad(9.143, \quad 4.020 \mathrm{ng} / \mathrm{ml})$ respectively,which disturb the normal spermatogenesis process.

In Conclusion, The current in vivo study confirm that mycotoxicosis significantly affect the male fertility via affecting the values of hormonal levels including testosterone and follicle stimulating hormone throughout disturbing spermatogenesis which is the main factor contributing in successful fertilization process.

\section{References}

CAST, Council for Agricultural Science and Technology. (2003): "Mycotoxins Risks in Plant Animal and Human Systems". Task Force Report No. 139. Ames, Iowa.

Closset, J. and Hennen G. (1988): Biopotency of highly purified FSH and $\mathrm{LH}$ on the testis of immature hypophysectomized rats. J Endocrinol, 119: 542.

Czerwiecki L, Czajkowska D and Witkowska-Gwiazdowska

A (2002): On ochratoxin $A$ and fungal flora in Polish cereals from conventional and ecological farms. Part 1: Occurrence of Ochratoxin A and fungi in cereals in 1997. Food Additives and Contaminants 19: 470-477. 
Doko, M.B.; Canet, C.; Brown, N.; Sydenham, E.W.; Mpuchane, S. and Siame, B.A. (1996): Natural co-occurrence of fumonisins and zearalenone in cereals and cerealbased foods from eastern and southern Africa. J. Agric. Food Chem. 44: 3240-3243.

Domsch K.H., Gams W., and Anderson, T.H. (1981): Compendium of Soil Fungi, vols. 1 and 2Academic Press, London.

Dowd, P.( 2004): Validation of a Mycotoxin Predicting Computer Program for U.S. Midwest Grown Maize in Commercial Fields. Proc. Aflatoxin \& Fungal Genomics Workshop. Mycopathologia 157:463 (abstr.)

Flannigan, B. (1977): Enumeration of fungi and assay for ability of degrade structural and storage components of grain. In: Walter, AHBiodeterioration investigation techniques. London: Applied Science;. pp. 185-199.

Henry, R. J. (1964): 'Clinical Chemistry: Principles and Technics', New York: Harper \& Row.

Joffe, A.Z. (1986): Fusarium Species: Their Biology and Toxicology. John Wiley and Sons, Inc., New York.

Mechoulam, R.; Brueggemeier, R.W and Denlinger, D.L. (1984): "Estrogens in insects". Journal Cellular and Molecular Life Sciences 40 (9): 942-944.

Munkvold, G.P.and Desjardins, A.E. (1997): Fumonisins in maize.
Can we reduce their occurrence? Plant Dis. 81: 556-564.

Nelson, P.E.; Tousson, T.A. and Marasas, W.F.O. (1983): Fusarium Species: An illustrated manual for identification. Pennsylvania State University Press, University Park.

Orsi, R.B.; Corrêa, B.; Possi, C.R.; Schammass, E.A.; Nogueira, J.R.; Dias, S.M.C. and Malozzi, M.A.B. (2000): Mycoflora and occurrence of fumonisins in freshly harvested and stored hybrid maize. J. Stor. Prod. Res. 36: 75- 87.

Pitt, J.I. (2000): Toxigenic fungi: which are important? Med. Mycol. 38: 17-22.

Pitt, JI (1985): Book, Advances in Penicillium and Aspergillus systematics. ISBN 0-306-42222-0 Record Number 19861316280.

Puntenney, S.B.; Wang,Y. and Forsberg, N.E.(2003): Mycotic infections in livestock: Recent insights and studies on etiology, diagnostics and prevention of Hemorrhagic Bowel Syndrome, In: Southwest Nutrition \& Management Conference, Pheonix, University of Arizona, Department of Animal Science, Tuscon, pp. 4963.

Raper K.P.and Fennel D.I (1977): "The Genus Aspergillus" $\quad$ R.E. Krieger Publishing Company, Huntington, New York.

Robledo-Robledo, E. (1991): Strategies for the prevention and control of fungi and mycotoxins in 
Central and South America. In: the number and function of Leydig Champ BR.

cells in immature

Sakuma, Y. (2009): Gonadal hypophysectomized rats. J. steroid action and brain sex Endocrinol, 120:97-106.

differentiation in the rat. J. Walker, W. H. and Cheng, J. Neuroendocrinol. 21 (4): 410-414. (2005): FSH and testosterone Teerds, K.J. , Closset, J. , signaling in Sertoli cells , Rommerts,R.F.G. ， De Rooij, Reproduction. 130: 15-28.

D.G. ， Stocco， D.M. ， Zirkin, B.R. and Chen, H. (2000): Colenbrander, B. , Gwensing,J. Regulation of Leydig cell and Hennen, G. (1989): Effects of steroidogenic function during aging. pure FSH and LH preparations on Biol. Reprod. 63(4): 977-981

تأثير السموم الفطرية على خصوبة هرمونات الأكورة

\section{الملنص العربي}

الفطريات المعزولة من العينات ؛ تم تحديدها فى ب با نوعا تنتمي إلى ^ أجناس و. كان

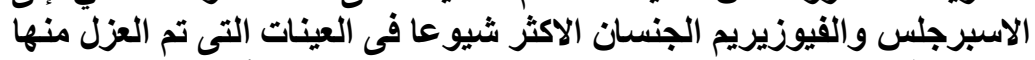

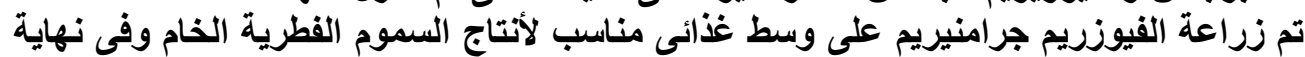

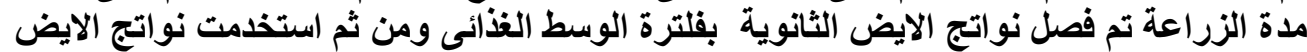

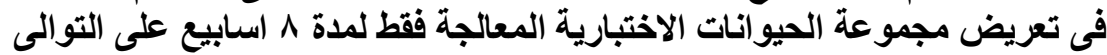

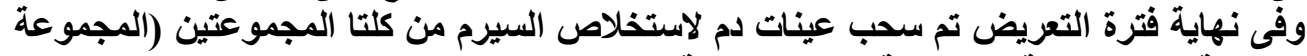

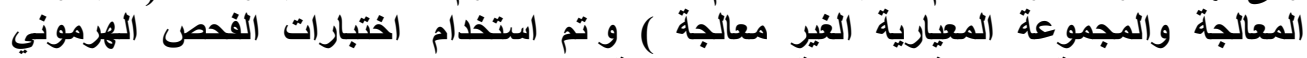

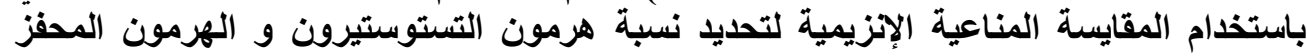

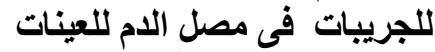

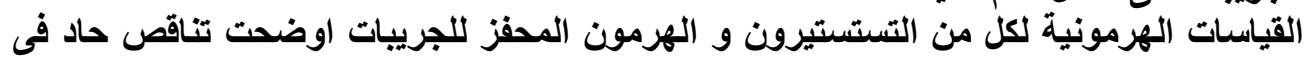

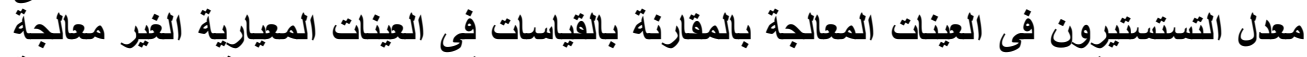

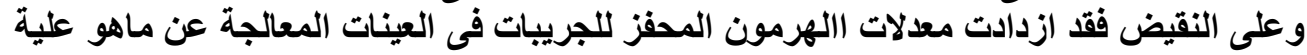

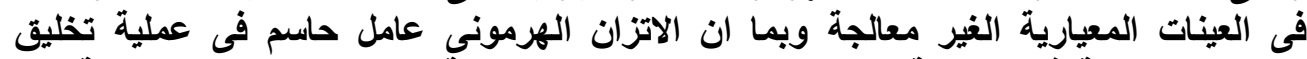

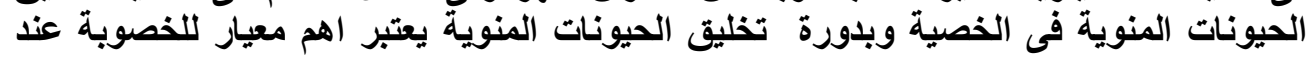

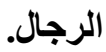

